\title{
ESPACIOS PÚBLICOS Y PRIVADOS DE SOCIABILIDAD E INTIMIDAD EN LA CIUDAD DE LEÓN EN EL SIGLO XVIII ${ }^{1}$
}

\author{
JUAN MANUEL BARTOLOMÉ BARTOLOMÉ \\ Universidad de León
}

Fecha de recepción: diciembre 2011

Fecha de aceptación: febrero 2012

El acercamiento a los aspectos de sociabilidad e intimidad de las sociedades modernas, aunque sean del siglo XVIII, sigue constituyendo un auténtico reto debido fundamentalmente a la problemática de las fuentes de información.

En este sentido, consideramos que las aportaciones de la que podemos denominar como la historia del consumo han contribuido de forma positiva a la hora de aproximarnos a dichas realidades ${ }^{2}$. Como también lo han hecho las realizadas por historiadores españoles cuyas opciones historiográficas oscilan entre la historia socioeconómica y los aspectos conectados con la vida diaria: espacio urbano, sociabilidad, alimentación, etc. ${ }^{3}$.

1. Este trabajo se encuadra en el proyecto de investigación del Ministerio de Ciencia e Innovación: Familia, identidad social, transmisión hereditaria y cultura material. Patrimonios, consumos y apariencias en la Castilla interior, 1600-1850 (HAR2010-21325-CO5-05).

2. Desde los primeros trabajos surgidos, hace más de diez años, bajo la dirección del proyecto de Bartolomé Yun Casalilla, hasta las publicaciones más actuales del grupo de investigación coordinado por Máximo García Fernández, como la de Dos Guimaraes SÁ, Isabel y García Fernández Máximo (directores): Portas Adentro, comer, vestir, habitar (ss.XVI-XIX), Coimbra, 2010; o la de NAVARRo MuÑoz, Daniel (ed.): Comprar, Vender y Consumir. Nuevas aportaciones a la historia del consumo en la España moderna, Valencia, 2011.

3. SAAVEDRA, Pegerto: La vida cotidiana en la Galicia del Antiguo Régimen, Barcelona, 1994; DuBERT GARCÍA, Isidro: Cultura popular e imaxinario social en Galicia, 1480-1900, Santiago, 2007. FRANCO RuBIO, Gloria (coord.): Cosas de la vida. Vivencias y experiencias cotidianas en la España Moderna, Madrid, 2009; NÚÑEZ ROLDÁN, Francisco (coord.):Ocio y vida cotidiana en el mundo hispánico en la Edad Moderna, Sevilla, 2007; PeÑa DíAz, Manuel: «La vida cotidiana en la época moderna: disciplinas y rechazos», en Revista de Historia Social, $\mathrm{n}^{\circ}$ 66, 2010, pp. 41-56; PÉREZ SAMPER, $\mathrm{M}^{\mathrm{a}}$ Ángeles (coord.): La vida quotidiana a través dels segles, Barcelona, 2002. Autores que son responsables de grupos de 
Al no poder contar con significativas fuentes literarias o relatos de viajeros ${ }^{4}$, nuestro trabajo se fundamentará principalmente en la información que procede de los fondos municipales y de los protocolos notariales, tanto poderes como sobre todo inventarios postmortem.

De acuerdo con lo señalado, los objetivos que nos planteamos son los siguientes: en primer lugar, estudiar los espacios públicos de sociabilidad en la ciudad de León en el siglo XVIII, fijándonos en su ubicación y sobre todo en las funciones de ocio y de reunión vecinal por motivos fiscales o de alojamiento de soldados. En segundo lugar, analizar los espacios privados, más familiares e íntimos, conectados con los lugares de residencia, las casas o cuartos de vivienda, de las familias de la burguesía de la ciudad leonesa. Y en tercer lugar, nos planteamos averiguar cuáles eran los espacios que se destinaban a la relación social y a la intimidad en las familias descritas y sus mutaciones, mediante la observación detallada del mobiliario y la decoración de dichas estancias $^{5}$.

\section{PUNTO DE PARTIDA: LA CIUDAD DE LEÓN EN SIGLO XVIII}

La ciudad de León a pesar del crecimiento demográfico del siglo XVIII tan sólo tiene unos 6.051 habitantes, en 1787, según el Censo de Floridablanca ${ }^{6}$. Es además una ciudad con una fuerte impronta señorial, clerical y burocrática, muy alejada del ideal de ciudad dinámica industriosa o mercantil ${ }^{7}$. Así, a mediados del siglo XVIII los 412 religiosos/as y colegiales no quedan muy distantes de los 526 artesanos. Y lo más llamativo, es que los 106 plumíferos (notarios y escribanos) igualen a los 107 comerciantes y tenderos o que sus 152 panaderos superen a los tejedores (65), sastres (83) o zapateros $(69)^{8}$.

No obstante, los últimos estudios realizados sobre familias de comerciantes y financieros de la capital, que desarrollan sus negocios en el siglo XVIII y primera mitad del XIX ${ }^{9}$, nos transmiten una imagen más dinámica en cuanto a sus volúmenes

investigación que, junto con el de Granada coordinado por ARIAS SAAVEDRA, Inmaculada, se centran en la temática señalada.

4. GómEZ HerAS, Natalia: «La vivienda doméstica española del siglo XVIII según los relatos de los viajeros británicos», en Revista Tiempos Modernos 21, (2010/2).

5. «Hoy a muchos historiadores no les interesa tanto el estudio de lo que se consume o las cantidades consumidas, cuanto el cómo se consume» Yun CASAlilla, Bartolomé: Prólogo a la obra Comprar, Vender y Consumir..., p. 11. A ello se puede añadir la relevancia de dónde se consume, ya que las prácticas de consumo, muy ligadas a la sociabilidad y a los espacios sociales de consumo, pueden ser formas de construcción de identidades.

6. PÉrez GarcíA, José Manuel: Demografía leonesa en el Antiguo Régimen (1500-1850), en La Historia de León, Vol. III. Edad Moderna, León, 1999, p. 192.

7. Ibidem, p. 193.

8. Rubio PÉREZ, Laureano: León, 1751. Según las Respuestas Generales del Catastro de Ensenada, Madrid, 1993.

9. BARTOlOMÉ BARTOlomé, Juan Manuel: Familias de comerciantes y financieros en la ciudad de León, 1700-1850, León, 2009. 
de negocios, con balances en general positivos y unos valores patrimoniales, conseguidos principalmente con el esfuerzo, que se asemejan a los de los comerciantes del interior peninsular ${ }^{10}$. Sin embargo, su tipo de negocio, fundamentalmente de comercio de tienda abierta de textiles o de hierro, y sus inversiones no serán nada innovadoras, ya que se dirigirán sobre todo a la adquisición de bienes raíces: tierras, inmuebles urbanos, imprescindibles para el desarrollo de su actividad, y no a las de carácter industrial. Sus estrategias matrimoniales serán endogámicas y su interés por controlar los mecanismos del poder, fundamentalmente el municipal, fueron muy escasos, por no decir nulos.

En definitiva, se trataba de una ciudad muy ruralizada, amurallada a cal y canto ${ }^{11}$ y con alguna sillería en las puertas de entrada que eran once; también algunos postigos la comunicaban extramuros ${ }^{12}$. De todas ellas sólo eran seis las puertas destinadas a la entrada de productos, destacando la Puerta de San Francisco y la Puerta del Peso ${ }^{13}$. El espacio urbano intramuros seguía conservando las características medievales: calles estrechas, callejuelas, plazuelas y plazas principales, en su mayoría sin empedrar ${ }^{14}$. Las plazas urbanas principales eran cuatro: la del Mercado ${ }^{15}$, la de San Marcelo ${ }^{16}$, la de la Catedral ${ }^{17}$ y la plaza Mayor.

\section{LOS ESPACIOS PÚBLICOS DE OCIO Y REUNIÓN DE VECINOS}

Somos conscientes que dejamos al margen espacios públicos donde tenían lugar también una sociabilidad promovida por actividades de carácter económico (mercados, ferias, etc.) o religioso (procesiones, etc.), pero consideramos que resulta de mayor interés centrarnos, por una parte, tal como ya hemos señalado y debido a un problema de fuentes, en los espacios o centros públicos destinados al ocio en el siglo XVIII:

10. Angulo Morales, Alberto: Del éxito en los negocios al fracaso del Consulado: la formación de la burguesía mercantil de Vitoria (1670-1840), 2000, Bilbao.

11. Había arrabales extramuros, en concreto siete, que cada vez serán más importantes.

12. Cubillo De la Puente, Roberto, La ciudad de León a mediados del siglo XIX, León, 2002, p. 23.

13. La de San Francisco actuaba para algunos productos, vino, aceite y vinagre, como lugar de almacenamiento y venta y la del Peso era por donde entraban muchos comestible en dirección al lugar donde estaba establecido el llamando Peso Real (también denominado Peso Merchán), situado en la Plaza Mayor. Cubillo De la Puente, Roberto: Comer en León. Un siglo de Historia:1700-1800, León, 2000, pp. 15 y 16.

14. Todavía a mediados del siglo XIX la mayoría de estas vías y espacios públicos estaban sin empedrar. Y sólo las calles Nueva y Plegaria eran anchas y bien alineadas. CUBILlO DE LA PUENTE, Roberto: La ciudad de León..., p. 23.

15. Se realizaba la venta de granos, legumbres y linaza.

16. Acogía las ferias anuales de San Juan, Todos los Santos y San Andrés, donde los ganados y las hilazas eran los principales artículos de transacción. CuBILlo DE LA PuENTE, Roberto: La ciudad de León..., p. 44.

17. En su parte sudoeste se celebraba un intenso comercio con leña y carbón los miércoles y sábados y en la Pascua de Resurrección, ya con hambre de carne, se realizaba un activo trasiego con animales jóvenes para consumir en la ciudad: terneros, corderos y cabritos. Ibidem. 
Plaza Mayor con sus espectáculos estrella que estaban representados por los festejos taurinos, Patio de Comedias y las tabernas. Y por otra parte, a los espacios donde se realizaba la reunión de los vecinos convocados por temas fiscales o militares.

La Plaza Mayor estaba rodeada de soportales y era el lugar preferido para el paseo y las reuniones en los abundantes días fríos y lluviosos y en las noches veraniegas. Además, era un centro de relevancia comercial, donde no sólo se vendía desde el pan, las frutas, las verduras y otros comestibles en puestos fijos que eran contratados al ayuntamiento, sino que en sus bajos, bajo la protección de los soportales, estaban establecidas las tiendas de los principales comerciantes de la ciudad. Y también se convertía en el espacio público de ocio más relevante, el preferido tradicionalmente para la celebración de los festejos taurinos ${ }^{18}$.

A lo largo del siglo XVIII hay noticias de festejos taurinos ${ }^{19}$, pero no fueron tan regulares como en el siglo precedente, ya que de forma esporádica se localizan en los años $1707,1732,1746,1749,1756,1757,1759,1768$ y 1783. De todos ellos, merece la pena destacar en primer lugar los de 1707, donde la corrida programada para el mes de mayo tiene que suspenderse debido a problemas que surgen con el cabido eclesiástico y su deseo de poner, al igual que hace el regimiento, un dosel con la efigie de los Reyes en sus balcones ${ }^{20}$. Finalmente, la ciudad de Léon tendrá sus festejos taurinos a mediados del mes de septiembre debido esta vez a motivos extraordinarios: por cuestiones reales ${ }^{21}$. En segundo lugar, en 1732, los festejos taurinos estuvieron acompañados de refrigerios, lo cual debía ser una práctica muy común, consistente en bebidas dulces, chocolate y bizcochos, con los que se agasajaban a las autoridades municipales, corregidor, regidores, y familiares y también a todo el público que quisiera concurrir al

18. Tan frecuentes y de gran éxito en el siglo XVII. VIFORCOS MARINAS, M ${ }^{\mathrm{a}}$ Isabel: El León barroco. Los regocijos taurinos, León, 1992. Para Valladolid ver AMIGO VÁZQUEZ, Lourdes: «Las fiestas de toros en el Valladolid del XVII. Un teatro de honor para las élites de poder urbanas», en Revista Studia Histórica, $\mathrm{N}^{\mathrm{o}} 26,2004$, pp. 283-319.

19. Las principales referencias se localizan en las libros de acuerdos municipales del Archivo Histórico Municipal de León (A.H.M.L.)

20. El problema surge debido a que el ayuntamiento acuerda festejar la victoria de las tropas del pretendiente Borbón en la batalla de Almansa con la celebración de una corrida de toros, pero cuando comienza la corrida el cabildo catedralicio puso en sus balcones también un dosel con las efigies de sus majestades, por lo que se decidió suspender el festejo taurino. A.H.M.L., Caja 64. Así, con enorme enfado el regimiento dio cuenta a su Majestad para «que se sirva mandar y proveer de remedio conveniente y que el cabildo eclesiástico no vaya ni pase contra el derecho y regalía de esta ciudad en nombre de su Majestad, mandando que dicho cabildo no pase a introducir semejantes novedades en los actos públicos y festivos por no tener derecho alguno, uso ni estilo, además de que dichos sus balcones en semejantes festejos no se pone ni sienta el cabildo en forma de comunidad, ni pudiera por la privación impuesta por su santidad a las comunidades eclesiásticas. Y que se les condene en todos los daños, costas y gastos que han causado y causaren, pidiendo que para uno y otro se manden librar los reales despachos que convengan...».Archivo Histórico Provincial de León (A.H.P.L.), Alonso Álvarez de Hevia, Caja 446.

21. En concreto, para celebrar el nacimiento de un príncipe. Además, las dos corridas serán acompañadas por «..fuegos y castillo y mojigangas.». A.H.M.L., Caja 64. 
mirador de la ciudad ${ }^{22}$. Y en tercer lugar, los que nos proporcionan mayor información son los de $1783^{23}$. El objetivo era que el pueblo tuviese una distracción ya que llevaba varios años clamando «...por alguna diversión popular de que han carecido y carecen de muchos años a esta parte...» ${ }^{24}$. De ahí, que el regimiento, a pesar de las dudas que tiene respecto a la buena gestión económica del evento dadas las experiencia anteriores, decide en la sesión celebrada en agosto de 1783 que se celebren en la ciudad tres funciones de novillos para los primeros días de septiembre (del 1 al 4 de septiembre) interpoladas con algunos toros de muerte ${ }^{25}$. El retraso en las fechas propuestas, primeros de septiembre frente a las más socorridas de agosto, se hace con la intención de conseguir un mayor público ya que así era posible atraer a la población que se dedicaba a las actividades agrícolas, tanto leonesa como de las localidades provinciales y regionales más próximas ${ }^{26}$.

Una vez que se realiza un presupuesto previo, el cual fue muy optimista ${ }^{27}$, se inicia una gestión ágil y eficaz, donde el funcionamiento fue a base de comisiones, nombrando en las mismas a personas que estaban ligadas al municipio de una u otra forma, que tienen como misión principal cumplir con las fechas previstas. Así, tras el contrato de los toreros en la ciudad de Burgos, la compra de toros y novillos, etc., lo que más nos llama la atención es el acondicionamiento del espacio público, la Plaza Mayor para el espectáculo: se traen desde diversos lugares del alfoz tierra y arena en carros, para cubrir el empedrado de la plaza y el recorrido total que debían efectuar $\operatorname{los} \operatorname{astados}^{28}$. Y al mismo tiempo, se sacan a alquiler los arcos «útiles» de la plaza, un total de 54, las barreras de fachada del consistorio y bocacalles hacia la plaza. En todos esos lugares estaba permitido instalar barreras, graderías (especialmente en los arcos) y rellanos, pero con la condición de que debían fabricarse con uniformidad e igualdad ${ }^{29}$. La expectación era tal que en unos pocos días, del 6 al 20 de agosto, se agotan todos los alquileres ${ }^{30}$. También, se alquilan los balcones que dispone el ayuntamiento en la antigua casa consistorial del siglo XVII, en total 19 que al precio de 200 reales cada uno fueron a parar a las familias distinguidas de la ciudad, además del corregidor e

22. El total del dinero gastado en el refrigerio que se sirvió a las autoridades municipales fue de 1.060 reales, incluyendo en el mismo también lo que se tuvo que dar a los mozos que lo sirvieron y la nieve que se gastó. El popular fue un poco más barato, 730 reales, y se dio en un día distinto, el de la corrida de novillos. Id., Caja 68.

23. Ya estudiados por CuBILlo DE LA PuenTE, Roberto: «Toros en la ciudad de León, 1783», Revista Tierras de León, $\mathrm{n}^{\circ}$ 104, León, 1998.

24. A.H.M.L., Caja 390.

25. CuBillo DE LA PuenTe, Roberto: «Toros en la ciudad de León...».

26. «...Convendrá que estas funciones se señalen en días oportunos, levantadas las eras...», Ibidem.

27. Ibidem.

28. En total 114 carros de arena que procedían de Puente Castro, Vilecha, Trobajo de Abajo, Armunia, La Corredera, Renueva. A.H.M.L., Caja 130.

29. Cubillo de la Puente, Roberto: «Toros en la ciudad de León...».

30. Para una mayor información sobre los precios, ver Ibidem. 
intendente, los cuales utilizaban generalmente dichos emplazamientos privilegiados para uso exclusivo de sus familias o de alguna amistad relevante ${ }^{31}$.

En definitiva, la plaza mayor leonesa se convierte en dichos días de septiembre del año 1783 en el lugar de sociabilidad por excelencia para los moradores de la ciudad e incluso para visitantes extranjeros. Es más, la inauguración de los festejos taurinos se celebró, la noche del 31 de agosto, con una proclama popular acompañada de una mojiganga, lo que obligó a iluminar la plaza mayor y encareció los presupuestos ${ }^{32}$. Y el éxito fue tal que el ayuntamiento decide que se aumente un día más a los programados para que se celebre un festejo cómico-taurino ${ }^{33}$.

Hasta tal punto la plaza mayor constituye el espacio público más importante de la ciudad que su estado de conservación preocupa a las autoridades municipales, en el sentido de que su imagen es un reflejo del ejercicio del poder del regimiento. De este modo, no debe sorprendernos que a comienzos del siglo XIX, en el año difícil de 1808, y movidos por el mandato del Consejo de Castilla de que se haga la proclamación de Fernando VII, el cabildo acuerde ante el deterioro de la plaza mayor ${ }^{34}$ que se pinten todos los edificios que forman el cuadro de la plaza «con la posible uniformidad» ${ }^{35}$.

Otro espacio público de reunión y diversión era el Patio de Comedias. Dicho patio o casa se situaba en otra de las plazas principales, la mencionada de San Marcelo, que era también el lugar donde se localizaba la casa municipal, donde tenía sus reuniones el ayuntamiento, la iglesia de su mismo nombre y el hospital de San Antonio Abad. A mediados del siglo XIX, en 1846, la casa de comedias dejó de existir ya que sobre su solar se inauguró un Teatro ${ }^{36}$. En realidad son muy escasas, por no decir nulas, las noticias referentes al Patio de Comedias que existió en la ciudad leonesa en la edad moderna y en concreto en el siglo XVIII. De su funcionamiento únicamente hemos localizado, por una parte, el contrato en 1770 de los cómicos de la compañía de la autora $\mathrm{M}^{\mathrm{a}}$ Antonia Iglesias ${ }^{37}$. Y por otra parte, la denuncia que por los mismos años, en 1778 , realiza el administrador general de las rentas provinciales ante el mismo Conde

31. De ellos al final cuando se realizaron las cuentas quedaron por pagar diez balcones, el corregidor y el intendente sí que pagaron los suyos, pero no así las familias Brizuela, Castañón, Valcarce, etc.. Ibidem.

32. En concreto la noche de iluminación estuvo acompañada de música, juguetes de estradillo, caballos de pasta y dominguillos. Costando todo ello la cantidad de 289 reales. A.H.M.L., Caja 130.

33. Junto a los dominguillos, etc., tuvo lugar la corrida y muerte de dos «chuetos» (chotos o becerros) por parte de un torero y cómico madrileño. CUBILlo DE LA PUENTE, Roberto: «Toros en la ciudad de León...».

34. El diez de agosto de 1808, «Por hallarse indecente y contra toda buena regla de policia...», A.H.P.L., Estebán Balbuena Díez, Caja 891.

35. Ibidem.

36. CuBILlo DE LA PuenTE, Roberto: La ciudad de León a mediados del siglo XX..., p. 44.

37. La expresada $\mathrm{M}^{\mathrm{a}}$ Antonia Iglesias había conseguido real despacho en marzo de 1770 con «título de autora de comedias», para el ejercicio del año de comedias que concluirá en el martes de carnaval del año 1771. Por ello, forma una compañía que es la que actúa en León, que se compone de: primer galán (que cobrará 30 reales de partida y dos reales diarios de ración), otros dos galanes (18 reales cada uno), primera dama (24 reales de partida y dos diarios de ración), apuntador (16 reales de partida y 5 reales diarios de ración) y cuarta dama (20 reales de partida). A.H.P.L., Pedro Hevia Lorenzo, Caja 750. 
de Aranda advirtiéndole no sólo de los abusos del ayuntamiento en la administración del patio de comedias, sino también de la mala conducta de los señores capitulares en las actuaciones, lo cual hacía sonrojar a «toda señora y hombre distinguido» ${ }^{38}$. Es más, según el denunciante ya se habían mandado desde Madrid las medidas que se debían adoptar para evitar en los sucesivo dichos agravios; sin embargo, seguía el rumor de que «seguiría el desorden en la presente temporada», ante lo cual recurre al corregidor interino $^{39}$. Como es lógico, las autoridades municipales niegan que hayan tenido dicha actitud y reafirman su buena dirección y gestión del patio de comedias ${ }^{40}$.

En cuanto a su estado, el deterioro debía ser una constante y más según avanzaba el siglo XVIII, ya que en 1784 es necesario realizar obras de reparación ${ }^{41}$ y en 1819 se hace referencia al patio de comedias como «inservible y derrotado tan del todo que sólo tenía las paredes y mala cubierta» ${ }^{42}$. La solución que propuso el ayuntamiento fue la cesión del patio de comedias a la Sociedad de Amigos del País ${ }^{43}$, para que la arreglasen y el dinero invertido lo pudiesen recobrar con el recargo de los precios de las entradas, pero dicha Sociedad se negó a aceptar dicha propuesta ${ }^{44}$.

Un tercer espacio de sociabilidad de los vecinos de la ciudad de León eran los pórticos de las parroquias, ya que según una tradición, que hundía sus raíces en la Edad Media, cuando existía un problemas que afectaba a los vecinos, bien de carácter fiscal o de alojamiento de soldados, eran los vecinos convocados por parroquias los que se reunían en las mismas, preferentemente en sus pórticos, con el objetivo de buscar una solución al problema planteado.

En el siglo XVIII la ciudad de León tenía una doble organización de los vecinos: por un lado, en parroquias para los que habitaban dentro de las murallas ${ }^{45}$; y por otro

38. «...los abusos, agravios y perjuicios que experimentaba el público de esta capital en el gobierno del patio de comedias y el potismo con que se apropiaban los señores capitulares otorgantes... con sus providencias ruidosas como tenía experimentado...». Id., Caja 749.

39. Ibidem.

40. «...la han dirigido y dirigen al mejor fin, paz y quietud de sus naturales y vecinos como es público y notorio...». Ibidem.

41. Las cuales se remataron en José Gutiérrez en la cantidad de 2.290 reales. Id., Antonio Díez, Caja 752. Es un pena que a pesar de que se hace referencia en el documento al expediente de las obras, éste no aparece. Quizás dicho expediente nos permitiría acercarnos a su estructura.

42. Id., Manuel García Álvarez, Caja 1037.

43. Para mayor información sobre la misma ver GONZÁLEZ MARTínEZ, Rosa María: La Sociedad Económica de Amigos del País de León, León, 1981. GonZÁLEZ GARCíA, Oscar: «De las Sociedades Económicas de Amigos del País a las Sociedades Patrióticas: León 1781-1823», Revista Estudios Humanísticos. Historia $\mathrm{N}^{\circ}$ 5, León, 2006, pp. 239-261.

44. A.H.P.L., Caja 1037.

45. Según Cesar Álvarez Álvarez, la fijación de los límites de las mismas dentro de la ciudad, en cuyo perímetro todos los habitantes quedaban vinculados a una de ellas, se estableció, en palabras de Sánchez Herrero, al menos desde el Sínodo de León de 1267, con el fin primordial de buscar un procedimiento para que todos pagasen cada año los diezmos a la misma parroquia, de tal modo que sólo se cambiaba de parroquia si se cambiaba de domicilio dentro de la ciudad. ÁlvArEz ÁlvarEZ, Cesar: La ciudad de León en la Baja Edad Media. El espacio urbano, 1992, León, p. 5. 
lado, en los arrabales también se organizaban en parroquias y éstas a su vez, en concejos con sus correspondientes ordenanzas.

A ella se superpone desde la Edad Media la organización en barrios ${ }^{46}$. De ahí, que la organización municipal establezca una división tanto de la ciudad como de sus arrabales en diferentes barrios que, normalmente, se solapan por coincidentes con la circunscripción territorial de las parroquias cuyas iglesias los presiden, lo que provoca que jurisdicción eclesiástica y municipal coincidan en un mismo espacio urbano ${ }^{47}$.

Los vecinos que moraban en el interior de las murallas se organizaban ya desde la Edad Media en las siguientes parroquias: San Martín, San Marcelo, Santa María del Camino, San Salvador de Palat de Rey, Santa Marina, San Pedro de San Isidoro ${ }^{48}$, San Juan de Santa María de Regla ${ }^{49}$. En el siglo XVIII siguen siendo las mismas parroquias, con una ordenación y prelación funcional heredada de la baja edad media ${ }^{50}$.

Los arrabales que se habían creado rodeando la ciudad y extramuros de ella eran cuatro $^{51}$ : San Salvador del Nido, San Pedro de los Huertos y San Lorenzo, los cuales forman un solo concejo; el arrabal de San Juan de Renueva; el de San Pedro de Puente Castro y el de Santa Ana, constituyendo los tres últimos cada uno un concejo que se identificaba con la respectiva parroquia.

Quizás también tenga un origen medieval la costumbre de reunirse los vecinos por parroquias. Pero lo realmente importante es que dicha práctica se sigue conservando en el siglo XVIII, donde son convocados a campana tañida, para tratar asuntos del «bien y utilidad común» ${ }^{52}$. Y para elegir de nuevo mediadores, a veces se les conoce con el

46. Aunque resulta difícil precisar qué designa exactamente la palabra barrio en los tiempos bajomedievales ya que muchas veces hace referencia y sustituye a parroquia, feligresía o colación y, en consecuencia, indica un territorio bastante amplio y de límites precisos, al menos para sus integrantes. Ibidem. Pag. 104.

47. Ibidem, pág. 105. Esta misma situación se produce en las ciudades castellanas y no muy lejanas de Burgos o de Salamanca. BONACHIA y CASADO, Hilario: Burgos en la Edad Media, Burgos, p. 27. GÓMEZ MARTín, Alfredo: «Cargos y oficios municipales en las ciudades de León, Zamora y Salamanca durante el reinado de Carlos III», en Revista Estudios Humanísticos. Historia, No 5, 2006, p. 182.

48. También se hará referencia a la misma como San Pedro de San Isidro.

49. A las que se añade desde el siglo XV Santa María de Villapérez, según Álvarez Álvarez, Cesar: El espacio urbano..., p. 105.

50. Número de parroquias que figura en 1732 y que se mantendrá a lo largo del siglo XVIII. Las cuatro intramuros que concentran a una mayor población se corresponden con las parroquias de San Martín, Nuestra Señora del Mercado, San Marcelo y San Juan de la Regla. En las dos primeras, sobre todo la de San Martín, es donde tiene lugar la actividad de carácter comercial, fundamentalmente de tienda abierta en los locales de la Plaza Mayor y de las Tiendas, y donde reside la burguesía comercial.

51. La mayoría de estos arrabales habían surgido en momentos anteriores a la Edad Media, aunque es en estos siglos cuando evolucionan hacia formas urbanas más claras y definidas. En la Baja Edad Media los arrabales eran los siguientes: el arrabal meridional, donde se localizaba el del Santo Sepulcro; el arrabal occidental, donde el más importante es de Renueva; el arrabal septentrional: San Mamés; y el arrabal Oriental. Álvarez Álvarez, Cesar: La ciudad de León..., pp. 65-77.

52. A.H.P.L., Juan Fuentes y Collantes, Caja 590. 
nombre de seises ${ }^{53}$, que serán los encargados de resolver las tensiones provocadas por el alojamiento de soldados o por problemas fiscales ${ }^{54}$.

Finalmente, podemos mencionar las tabernas, las cuales constituían un espacio de reunión, diversión y de distensión, no exento de peleas, dada su clientela y el consumo de alcohol. Es una pena la falta de información sobre las mismas, pero que se convertían en los centros principales del devenir diario nos lo demuestra la abundancia de las mismas, ya que la venta del vino se realizaba por la doble modalidad de obligados y cosecheros o «herederos de viñas». Los primeros, según la información que nos suministra el catastro ensenadino, no suelen realizar su venta en tabernas previamente determinadas en la ciudad, sino que «los abastecedores las arriendan cómo y dónde les parece $\rangle^{55}$. No obstante, sabemos que a pesar de esta ocultación del Catastro lo normal es que tuviesen su propia taberna ${ }^{56}$ y así, por ejemplo, en 1729 son doce los cosecheros a los que se les permite la venta de vino ${ }^{57}$.

\section{LOS ESPACIOS PRIVADOS: LAS CASAS Y SUS DEPENDENCIAS DE LA BURGUESÍA LEONESA}

La fuente sobre la que vamos a realizar este estudio son principalmente los inventarios postmortem, los cuales presentan grandes deficiencias ya que por una parte, no todos especifican las dependencias en las que están ubicados los bienes a inventariar, y cuando lo hacen tampoco prestan demasiada atención en la definición de las mismas, hasta el punto de que a primera vista da la impresión de que se omiten los espacios donde no hay objetos que inventariar y tasar, como por ejemplo los pasillos. Y por otra parte, es muy frecuente también la práctica de inventariar y tasar los objetos agrupados por su tipología (textiles, mobiliario, alhajas, cuadros, etc.) y no según su ubicación en los espacios o dependencias de la casa.

No obstante, sí que contamos con una muestra significativa, un total de 12 inventarios ( 4 de la burguesía comercial y 8 de la burguesía que podemos considerar administrativa y de profesiones liberales), que nos van a permitir acercarnos a los espacios privados de carácter doméstico.

El centro de ubicación de las casas de los comerciantes, la mayoría con comercio de tienda abierta, era el barrio leonés de San Martín: Plegaria, Platerías y sobre todo la plaza de San Martín, también denominada de las Tiendas, y la Plaza Mayor.

53. Los seises consideramos que hace referencia a vecinos que gozan de un mayor prestigio y autoridad moral entre sus convecinos, pero desconocemos la forma en qué se procede a su nombramiento. Es curioso que dicha denominación haya pasado posteriormente a las cofradías de carácter religioso.

54. Para mayor información sobre el tema ver BARTOLOMÉ BARTOLOMÉ, Juan Manuel: «De la administración particular a la gestión por el común de vecinos de las rentas provinciales de la ciudad de León en el siglo XVIII», en Studia Histórica. Historia Moderna, No 31 Salamanca, 2009, pp. 305-323.

55. A.H.P.L., Catastro de Ensenada, Cajas 8278-82.

56. La de José Casado estaba situada en San Salvador del Nido y la familia Fernández Chicarro tenía dos: una en la calle Zapaterías y otra en El Peso (Plaza Mayor). A.H.M.L., Caja 519.

57. Ibidem. 
A pesar de las limitaciones de las fuentes, sí podemos señalar que las casas de los comerciantes leoneses son amplias, luminosas ${ }^{58}$ y constan, en general, de dos pisos $^{59}$, que miran siempre a las calles o a las plazas, para facilitar el comercio ${ }^{60}$ y que en algunos casos aprovechan incluso para su edificación la muralla romana y medieval ${ }^{61}$. El primer piso se dedica tanto al comercio como a la función de residencia de la familia, lo cual resulta lógico dado el carácter público del mismo y al mismo tiempo también facilitaba una estancia privilegiada para cuando llegase el calor de los meses de verano. Así, respecto al negocio figura la tienda, la trastienda y los almacenes, como también la bodega y cuadras ${ }^{62}$. Todo ello acompañado de las respectivas salas, algunas de carácter principal, que a su vez tienen en la misma pieza una o varias alcobas y una antesala ${ }^{63}$. Hasta en algunas viviendas también se localizaba una cocina en el primer piso, con su correspondiente despensa ${ }^{64}$, pero lo más normal es que se situase en la segunda planta.

El segundo piso es el reservado exclusivamente para la residencia de la familia y de forma esporádica para los criados/as, los cuales vivían más frecuentemente en las dependencias bajas, sobre todo si se trataba de los más abundantes varones con una dedicación más de cara al mundo de los negocios que a la doméstica ${ }^{65}$.

58. En general son casas de su propiedad que tienen una tasación muy alta. Como por ejemplo la de Ramón Selva que es valorada en su inventario postmortem en 81.200 reales. Además, en los inventarios sí que se suele valorar las vidrieras de las ventanas y los balcones. A.H.P.L., Ildefonso García Álvarez, Caja 1167.

59. Imagen, por lo tanto, muy distinta a la descrita por los viajeros británicos, que consideramos era más propia de ciudades más relevantes y de grupos sociales urbanos inferiores: de edificios de viviendas donde convivían varias familias de vecinos, cada una en un cuarto independiente, que no tenían ningún tipo de relación entre ellas. GómEz HerAs, Natalia: «La vivienda doméstica española...», p. 25.

60. Al igual que sucede en Lisboa, donde en la segunda mitad del siglo XVIII las transformaciones se abren hacia el exterior para lograr también mayores contactos mundanos y sociales. MADUREIRA Nuno Luis: Lisboa 1740-1830. Cidade: Espaço e Quotidiano, Lisboa, 1992, p. 130.

61. El comerciante Miguel Hernández de Medina, el cual tiene un cuarto que se denomina «cuarto del cubo». A.H.P.L., Félix González Mérida, Caja 867.

62. No es muy frecuente, pero sí que se menciona en la casa de Jolís. Id., Pedro Ballesteros Ginovés, Caja 1151.

63. Se trataría, por lo tanto, de la organización típica del Antiguo Régimen, tal como nos señal el viajero de principios del siglo XVII, Bartolomé Joly, el cual señala: «...Desde la sala se entra en los cuartos, aunque tan sólo para acostarse porque son oscuros y sin chimenea, algunos sin ventanas, no acompañados de guardarropas o gabinetes, sino semejantes a los que nosotros llamamos tabucos, ellos los llaman alcobas, que significan lugar ciego. Si hay en ellos alguna ventana, es un ventanuco u otro pequeño agujero. Otros viajeros describen las alcobas como espacios destinados exclusivamente para dormir, las cuales estaban levantadas dentro de una sala, y debían ser necesariamente pequeñas, ciegas e interiores para facilitar su caldeamiento por medios naturales y sin necesidad de recurrir a estufas, braseros o chimeneas, que producían humo y eventualmente gases tóxicos para el ser humano. GARCÍA MERCADAL, J., Viajes de extranjeros por España y Portugal, Madrid, 1952, pp. 72-73.

64. Caso de José Pablos Salán. A.H.P.L., Antonio Ginoves Martín, Caja 1011.

65. No suelen mencionarse en los inventarios postmortem cuartos de criados/as, tan sólo hemos encontrado una sola referencia en el inventario del comerciante Ramón Selva, especificando que se trata de una criada. Id. Ildefonso García Álvarez, Caja 1167. 
En el siglo XVIII, sobre todo en la segunda mitad, las antesalas son dependencias de paso previo a las salas, adornadas con espejos y cuadros de temática preferentemente religiosa, que a su vez también se utilizan para guardar en sus arcas, arquillas, archivos y alacenas, tanto ropa de cama, de casa y de vestimenta personal, como las piezas de la cubertería ${ }^{66}$.

Las salas que se denominan principales por lo general son espacios multifuncionales donde predomina lo antiguo y sólo esporádicamente llegará algún elemento nuevo. De este modo, hay una importante ocupación del espacio que sirve tanto como lugar de recepción de visitas, como también para $\operatorname{comer}^{67}$, trabajar y guardar ropa y cubiertos de la casa. Así es frecuente la presencia de mesas, acompañadas por abundantes taburetes más que por sillas ${ }^{68}$, junto con escritorios, bufetes, archivos y arcas principalmente de nogal ${ }^{69}$. Tampoco faltan los escaparates pintados con figuras religiosas en su interior, los cuadros y láminas de temática religiosa en las paredes y las cortinas para las ventanas ${ }^{70}$. No obstante, esta imagen tan tradicional de las salas principales se rompe ya con la presencia muy testimonial de dos elementos decorativos nuevos: los espejos y los relojes de pared ${ }^{71}$.

Las otras salas más secundarias se destinan principalmente a lugares de trabajo, con presencia de mesas, generalmente de madera de calidad más inferior, escritorios, bufetes y en algunos casos tampoco viene mal la existencia de alguna cama.

Las alcobas principales, piezas como ya hemos visto unidas a las salas, son el lugar reservado para el descanso, sobre todo nocturno, acogiendo el denominado

66. Como ejemplo, en la antesala, que da acceso a la sala principal, de Miguel Fernández Chicarro, en 1782, encontramos una arca de nogal con cerradura y llave, una arquilla de chopo negra también con cerradura y llave, un archivo de nogal que contiene ropa personal, de cama y casa (paños de manos, manteles, etc.) y dinero: «...en dos bolsillos, uno de seda y otro de pellejo, se encontraron en monedas de oro y plata dos mil doscientos cincuenta y nueve reales» y una alacena de chopo pintada con dos cajones, en la que se recogen los platos, fuentes, vasos, etc. Las paredes de la antesala se decoran con cuadros y sobre todo láminas de santos, donde sobresale un cuadro grande con su marco negro de Nuestra Señora, y como novedad «...cuatro láminas de pintura de Francia tasadas en cuatro reales...». Id., Manuel Rico, Caja 701.

67. Los viajeros británicos del siglo XVIII criticaban la inexistencia del comedor como una estancia en sí misma, y si lo era, la poca atención que se le concedía. GONZÁLEZ HERAS, Natalia: «La vivienda doméstica española...», p. 16.

68. En Lisboa se reducen en los salones los taburetes por combinaciones de sillas, poltronas o sillas acabrioladas. MADUREIRA, Nuno Luis, Lisboa 1740-1830..., p. 128.

69. En la sala principal de José Casado Valcarce, en 1797, hay los siguientes muebles: un bufete de nogal, diez taburetes de baqueta, una silla poltrona, un escritorio, un arca de nogal, un archivo de nogal. A.H.P.L., Domingo Suárez de Velasco, Caja 973.

70. Es el caso de Miguel Fernández Chicarro, con una sala principal que alberga dos escaparates pintados con su cristal y dentro de ellos:»...Un Niño Jesús con sus diademas de plata y la imagen de Nuestra Señora de la Concepción con su corona de plata...». Id., Manuel Rico, Caja 701.

71. Al igual que sucede en las salones de los negociantes y mercaderes de Lisboa. MADUREIRA, Nuno Luis, Lisboa, 1740-1830..., p. 128. En la sala principal de la casa de Miguel Fernández Chicarro hay seis espejos, dos de los cuales con sus «...marcos acharolados con sus lunas y candeleros tasados en 100 reales.». Ibidem. 
«lecho cotidiano», es decir, la cama del matrimonio y los colchones y la ropa que la viste ${ }^{72}$, la cual suele ser muy abundante, sobre todo los colchones ${ }^{73}$. Estos espacios íntimos suelen tener también una cama para niños, los cuales compartirían la misma habitación hasta una edad que desconocemos, y unos muebles de acompañamiento simples y escasos: algunas mesas y sillas, que podrían tener la función tan frecuente de comer en la propia alcoba o de aprovechar para realizar algún trabajo. Finalmente, tampoco es muy excesiva la decoración de sus paredes con cuadros religiosos ${ }^{74}$.

Las demás alcobas que hay en las casas, junto con los cuartos, son espacios únicamente reservados al descanso, dormir, destacando la menor privacidad frente a las principales ya que lo más común es que haya dos o más camas, sin apenas mobiliario de complemento ni objetos decorativos.

Finalmente, las cocinas no sólo eran el espacio destinado a la preparación de los alimentos, sino que también la existencia en las mismas de bancos y mesas, generalmente de chopos, nos lleva a pensar que también se utilizaban para comer y con una mayor frecuencia que las salas principales.

A diferencia de lo que sucedía con las familias de la burguesía comercial, cuyo emplazamiento residencial estaba motivado por las necesidades de sus negocios, nos resulta más difícil el poder identificar determinados barrios o parroquias como lugares preferidos en los que se ubicaban las casas de la burguesía administrativa y de profesiones liberales. Tampoco la información que nos proporcionan los documentos, sobre todo los inventarios postmortem, resulta muy esclarecedora y más cuando se trata de viviendas que no todas son propiedad de dichas familias, ya que como es lógico dada la profesión y el posible carácter no definitivo de la estancia prefieran alquilarlas. No obstante, los barrios más solicitados siguen siendo los más próximos a la Catedral y la Plaza Mayor, conviviendo con las casas y familias de la burguesía comercial, y también en las parroquias de San Marcelo, Santa Marina, San Pedro de San Isidoro y San Juan de Santa María de Regla. Es decir, parroquias que se situaban en el interior de las murallas.

A pesar de las limitaciones expuestas por las fuentes, podemos señalar que la burguesía administrativa y de profesiones liberales y sus familias residían no en cuartos de

72. En las localidades campesinas leonesas de Tierra de Campos, Sahagún, es frecuente la práctica hereditaria de que la viuda reciba una vez fallecido el marido y roto el matrimonio, la totalidad del lecho cotidiano que han compartido.

73. En la alcoba principal de Miguel Fernández Chicarro hay «...una cama de madera de nogal con su cabecera y colgadura que consta de cuatro colchones, dos sábanas, cobertor, colcha y almohadas». A.H.P.L.., Manuel Rico, Caja 701.

74. En el ejemplo anterior junto a las camas hay cinco sillas, dos de paja para hombre, una mesa de nogal, tres estampas de papel, tres láminas y un cuadrito. Ibidem. 
una misma vivienda ${ }^{75}$ sino en casas individuales de construcción en general antigua ${ }^{76}$, las cuales eran lógicamente de menor tamaño que las de la burguesía comercial, ya que no necesitan emplazar sus negocios, pero que también en la mayoría de los casos tenían dos pisos: el primero donde se situaba además del portal, la bodega, los bodegones y las paneras, y el segundo reservado más a residencia personal y de la familia, con la presencia de «corredores del muro», lo que nos señala que también podían aprovecharse los muros de la muralla medieval de la ciudad. De ahí, que aunque tan sólo en un inventario postmortem se especifique de forma concreta la existencia de dos pisos en la casa, ${ }^{77} \sin$ embargo, es muy frecuente en los demás las referencias a: «sala alta», «corredor del muro alto», «escalera principal», etc.

Los espacios destinados a residencia constaban de la típica estructura ya analizada del Antiguo Régimen: antesalas, salas y alcobas que salían de las propias salas. En definitiva, espacios muy conectados entre sí, sin pasillos intermedios y sin puertas, que era el esquema que se cumplía sin grandes alteraciones para el siglo XVIII en las casas ya estudiadas de la burguesía comercial. Sin embargo, la burguesía administrativa y de profesiones liberales en el siglo XVIII también prefiere espacios más independientes, no tan conectados. Así, es cierto que todavía hay alcobas que se localizan unidas a las salas, pero también se especifican «cuartos», bien inmediatos a la alcoba y sobre todo de forma totalmente independiente, destinados a «dormitorio», «criados» o al verano: «cuarto de verano ${ }^{78}$. Por lo tanto, esta tendencia propia de la burguesía de tener espacios más aislados y que favoreciesen la intimidad aparecerá ya de forma clara en la burguesía administrativa y de profesiones liberales en el siglo XVIII, sobre todo en la segunda mitad, adelantándose a la burguesía comercial.

También harán acto de presencia de forma más temprana que en la burguesía comercial, en la segunda mitad del siglo XVIII, los nuevos espacios domésticos burgueses: los «nuevos salones» ${ }^{79}$ que conviven con los antiguos «estrados» ${ }^{80}$, pero que poco a poco los van desplazando y los «gabinetes», los cuales tenían todavía una fun-

75. La convivencia de varias familias, cada una en un cuarto independiente, que no tenían ningún tipo de relación entre ellas es un modelo de vivienda de la zona urbana española del siglo XVIII que despertó la sorpresa de algunos viajeros británicos, como E. Clarke. GonZALEZ HERAS, Natalia: «La vivienda doméstica...», p. 25.

76. Ya que sólo hemos localizado en 1824 una casa de nueva fabrica, se trata de la de don Joaquín Álvarez Escaja, valorada en 24.923 reales. A.H.P.L., Felipe Morala Rodríguez, Caja 1065.

77. Inventario de don José González Luna, realizado en 1849. Id., José Casimiro Quijano, Caja 903.

78. Don Jerónimo José de la Plaza en 1781, administrador del excusado y casa diezmera, por ejemplo, tiene «dos cuartos de verano» y «un cuarto de las criadas» que no están conectados a ninguna pieza de la casa. Además, tiene tres salas y sólo en una de ellas, que no es la principal no la de recibimiento se hace relación a «alcobas». Id., José García Álvarez Ocón, Caja 793.

79. En la casa de Don Manuel García de Brizuela, abogado de los Reales Consejos, en el año 1777, hay una «sala estrado» de la que salen alcobas y una antesala, pero también un «salón nuevo», totalmente independiente. Id., Pedro Hevia Lorenzana, Caja 749.

80. El estrado era el espacio que las mujeres ocupaban después de cumplir con sus obligaciones domésticas. Un espacio para el descanso y el reposo, sin abandonar el hogar al que siempre debían estar atentas. Para 
ción más de despacho que de espacios más íntimos femeninos ${ }^{81}$. Finalmente, como es lógico dadas sus profesiones son muy abundantes los «cuartos de estudio», que ya a mediados del siglo XVIII también empiezan a denominarse «cuartos despacho» ${ }^{82}$, ubicados de forma estratégica, dados los rigores invernales leoneses, en contacto con la cocina.

En definitiva, casas más modestas en cuanto a las dimensiones que las de la burguesía comercial, pero con una organización del espacio interior desde el siglo XVIII, sobre todo segunda mitad, más propio de las tendencias de las nuevas modas burguesas, buscando mayor intimidad y comodidad.

En las segunda mitad del siglo XVIII aparecen antesalas, pero en menor medida que en la burguesía comercial, siendo sustituidas por las denominadas «salas de recibimiento» ${ }^{83}$, hasta el punto de que dejan de cumplir la anterior función de ser simples lugares de paso previos a las salas y se constituyen en auténticos espacios donde se recibe a las visitas tanto de parientes, amigos, como también a las de carácter profesional, convirtiéndose, por lo tanto, también en lugares de trabajo, con la presencia de mesas y sillas de nogal ${ }^{84}$. También son más innovadoras en la decoración ya que junto a la preeminente religiosa aparecen cuadros de pinturas de reyes y bodegones ${ }^{85}$. Finalmente, siguen cumpliendo la función de guardar ropa de vestir y de casa en sus archivos y arcas, preferentemente también de nogal.

La sala de estrado, muy escasa ya que sólo hemos localizado una, y sobre todo las salas principales, son las dependencias más nobles de la casa y también las más polivalentes, donde no sólo se recibían visitas, sino que también se utilizaba para trabajar, comer y guardar ropa u objetos de valor. De ahí, la elevada cantidad de piezas de mobiliario y de decoración que hacen muy difícil la presencia y la relación humana: mesas, taburetes, sillas en menor medida, escritorios ${ }^{86}$, bufetes, baúles, acompañados por escaparates con figuras religiosas, cornucopias y cuadros de temática religiosa.

mayor información ver SoBALER SECO, Ma Ángeles: «Espacios femeninos en la Castilla del Antiguo Régimen. Cultura material y sociabilidad en el estrado», en Portas adentro..., p. 153.

81. Al igual que sucedía en la burguesía comercial leonesa y en los mercaderes y negociantes de Lisboa en la primera mitad del siglo XIX. MADUREIRA, Nuno Luis: Lisboa...

82. Como, por ejemplo, el de don Jerónimo José de la Maza, en 1781. A.H.P.L., José García Álvarez Ocón, Caja 793.

83. Pueden equivaler a «las salas de recepción» que hacen referencia los viajeros británicos, que se caracterizaban por albergar un nutrido conjunto de sillas colocadas junto a las paredes. GONZÁLEZ HERAs, Natalia, «La vivienda doméstica española...», p. 13.

84. En la «sala de recibimiento de la casa» de don Jerónimo José de la Maza, administrador del excusado y casa diezmera, en el año 1781, hay una mesa con tres cajones y seis sillas de brazos también de nogal forradas en badanilla. A.H.P.L., José García Álvarez Ocón, Caja 793.

85. «Cuatro países fruteros con marcos negros... y otros dos viejos sin marcos pinturas de Felipe II y una reina...». Ibidem.

86. Por lo general de fábrica de Salamanca, aunque en el caso del médico titular de la ciudad de León, don Andrés de Meyre, los dos escritorios que tiene en la sala principal son de fábrica de Asturias, valorados en 100 reales. Id., Pedro Díez Canseco, Caja 1020. 
No obstante, en este panorama tradicional aparecen ya algunas novedades, aunque de forma muy testimonial, como son los espejos de medio cuerpo ${ }^{87}$, los frisos de Inglaterra y los canapés de hombre ${ }^{88}$.

Las alcobas principales son los espacios reservados preferentemente para el descanso y la intimidad, sobre todo nocturna, donde se localizan las camas y sus complementos, destacando la presencia de colchones, pero en un número inferior a los de la burguesía comercial. Se trata de dependencias muy sencillas donde se utiliza para guardar, sobre todo la ropa personal, cofres, arcas y baúles y son muy escasas las piezas más íntimas como las mesas y mesitas ${ }^{89}$. Tampoco es muy abundante la decoración, preferentemente religiosa y algún espejo pequeño.

Mención aparte merecen los «cuartos de estudio» o ya también denominados «cuarto de despacho», emplazados al lado de la cocina y con braseros y felpones, para poder combatir mejor las bajas temperaturas invernales ${ }^{90}$. Son dependencias dedicadas fundamentalmente al trabajo, conectado con sus profesiones, donde abundan como es lógico los archivos, escritorios, escribanías, mesas y sillas principalmente de nogal, pero donde llama la atención la ausencia de librerías y libros.

Finalmente, las cocinas se utilizaban no sólo para preparar y elaborar los alimentos, sino también para comer en ellas, como lo demuestra la existencia de mesas, escaños y bancos de respaldos en las mismas ${ }^{91}$.

En conclusión, a través de este estudio hemos intentado acercarnos a los espacios tanto públicos, los cuales resultan más conocidos a nivel historiográfico, como también a los más novedosos de carácter privado de la sociabilidad e intimidad de la ciudad de León en siglo XVIII y de forma más concreta de la burguesía. No obstante, en lo que se refiere a las mutaciones en los espacios de uso doméstico habrá que esperar para poder apreciarlas con mayor intensidad a la primera mitad del siglo XIX, que es cuando consideramos que se produce la formación de una identidad burguesa más marcada.

87. Al igual que sucedía en los comerciantes leoneses y en los salones de los negociantes y mercaderes de Lisboa, MADUREIRA, Nuno Luis: Lisboa...

88. En la sala principal de don Jerónimo José de la Maza en donde se hallan principalmente dichas novedades: dos canapés de hombre de nogal, pie de anca de rana, respaldo de nogal, forrados en esparragón encarnado, tasados en 280 reales; un friso de doce varas encerado de Inglaterra con varias pinturas y países, valorado en 160 reales. A.H.P.L., José García Álvarez Ocón, Caja 793.

89. Como, por ejemplo, en el médico don Andrés de Meyre, que tiene una silla y una mesica de cama. Id., Pedro Díez Canseco, Caja 1020.

90. En el cuarto segundo de estudio de don Manuel García Brizuela, abogado de los Reales Consejos, en el año 1777, hay, además del necesario brasero, diez felpones y un pellejo de oso. Id., Pedro Hevia Lorenzana, Caja 749.

91. Al igual que sucedía con la burguesía comercial. 